\title{
DIMENSIONS OF CREDIT RISK AND THEIR RELATIONSHIP TO ECONOMIC CAPITAL REQUIREMENTS
}

\author{
Mark Carey \\ Working Paper 7629 \\ http://www.nber.org/papers/w7629 \\ NATIONAL BUREAU OF ECONOMIC RESEARCH \\ 1050 Massachusetts Avenue \\ Cambridge, MA 02138 \\ March 2000
}

This paper was prepared as part of the NBER Project on Prudential Supervision of Financial Institutions and presented at the NBER conference in January 2000. The views expressed herein are not necessarily those of the Board of Governors, other members of its staff, the National Bureau of Economic Research, or the Federal Reserve System. Thanks to Paul Calem, Ed Ettin, Mark Flannery, Michael Gordy, Mark Hrycay, Patricia Jackson, David Jones, John Mingo, and Bill Treacy for useful conversations.

(C) 2000 by Mark Carey. All rights reserved. Short sections of text, not to exceed two paragraphs, may be quoted without explicit permission provided that full credit, including $(\odot$ notice, is given to the source. 
Dimensions of Credit Risk and Their Relationship to Economic

Capital Requirements

Mark Carey

NBER Working Paper No. 7629

March 2000

\begin{abstract}
$\underline{\text { ABSTRACT }}$
Now in prospect is a major revision of international bank capital regulations that would embody recent advances in credit risk measurement and management. Previous regulations have been simpler in structure, with a primary goal of getting capital requirements right on average, and thus have largely ignored the difference between average and marginal. This paper presents evidence that explicit treatment in new regulations of several important dimensions of credit risk is necessary. If such dimensions are compressed or ignored, capital arbitrage activities by banks are likely to continue, leading to an increase in bank failure rates over time.
\end{abstract}

\author{
Mark Carey \\ Mail Stop 153, \\ Federal Reserve Board \\ Washington, DC 20551 \\ and NBER \\ (202) 452-2784 (voice) \\ (202) 452-5295 (fax) \\ mcarey@frb.gov
}


A major revision of commercial bank capital adequacy regulations is now being developed. Regulators are likely to change the treatment of a variety of types of risk, but a primary focus of their effort is improvement of the manner in which the 1988 Basel Accord handles credit risk. Currently, assets making vastly different contributions to portfolio credit risk often receive similar regulatory capital treatment. Because equity is an expensive source of finance, the resulting wedges between regulatory and economic capital allocations have created strong incentives for banks to restructure their activities and balance sheets. For example, many bank-sponsored securitizations are directed at removing from the balance sheet those assets with relatively high marginal regulatory capital requirements but which contribute relatively little to portfolio credit risk, such as credit card loans and loans to low-risk corporate borrowers (such activity is often called "capital arbitrage"). In contrast, assets for which regulatory capital requirements are too low tend to remain on the balance sheet. By boosting capital ratios, the 1988 Accord reduced bank insolvency risk in the years immediately after its adoption, but if current trends continue to their logical conclusion, an unmodified Accord could in the end have the perverse effect of greatly increasing banks' portfolio risk postures and bank failure rates. Moreover, any revision of the Accord that preserves first-order differences between regulatory and economic capital requirements probably will be unsustainable in the long run. ${ }^{1}$

In a recent paper (Basel 1999), the Basel Supervisors Committee briefly outlined three approaches to capital regulation: 1) a revised "standardized" approach architecturally similar to the current Accord that would leave in place many distortions; 2) a "full models" approach, similar to that now available for market risk, in which a bank's internal models would compute required regulatory capital for credit risk; and 3) an "internal ratings" approach in which credit risk capital would be computed using formulas involving various relevant portfolio characteristics, like the fraction of loans assigned each internal rating. The latter two approaches both would attempt to make regulatory capital approximate economic capital, but in the internal ratings

1 "Economic capital requirements" for credit risk means the capital needed for a portfolio such that the chance that credit losses exceed capital is no more than a specified small probability. In many circumstances, economic capital would be the same as that needed to finance an asset or portfolio in a free-market transaction with informed counterparties. 
approach the parameters and architecture of the system would be set by regulators whereas in the full models approach they would be set by banks and reviewed by regulators. ${ }^{2}$

A principal barrier to adoption of the full models and internal rating approaches is technical uncertainty about the portfolio characteristics that drive credit risk. At least initially, simpler formulas and models are preferred for their lower cost of implementation. However, to avoid a continuation of serious distortions, regulations must take into account all first-orderimportant determinants of portfolio credit risk. The main body of portfolio theory, which was developed largely for equity portfolios and which suggests that correlations of individual loan credit losses with systematic factors are the only relevant influence on portfolio risk, is of limited use in identifying such determinants. The floating-rate loan portfolios typical of banks have a large credit downside but only modest upside potential, which causes the credit loss distributions for such portfolios to be skewed and to have very long bad tails (Figure 1). Though loss correlations are important, factors like individual asset risk, portfolio size, and the behavior of defaulted assets may also be important determinants of debt portfolio bad-tail loss rates.

Empirical uncertainty about the dimensions of credit risk exists among policymakers because relatively few publicly available studies exist and because most such studies have used one of the extant credit risk models to produce evidence. Models like CreditMetrics (Gupton, Finger and Bhatia 1997) and the Oliver Wyman-like approach described in Ong (1999) estimate loss rates at different percentiles of the bad tail conditional on portfolio composition. However, model results are quite sensitive to assumptions about values of parameters that are extremely difficult to observe, test, or even develop intuition about (Gordy 2000a). It is difficult to know the reliability of evidence such models produce about the influence of a given portfolio characteristic on bad tail loss rates and thus on economic capital requirements.

This paper uses the Monte Carlo resampling method of Carey (1998) to provide nonparametric empirical evidence about the practical importance to portfolio bad tail loss rates of

${ }^{2}$ All three approaches must specify required capital for risks other than credit, like interest rate risk or operational risk. Although the full models approach has many desirable properties, practical barriers to its implementation are such that the Basel Supervisors Committee is focusing its attention on the standardized and internal rating approaches for possible near-term implementation. 
several different asset and portfolio characteristics. This bootstrap-like method simulates the likely range of loss experience of a portfolio manager who randomly selects assets from those available for investment, while at the same time causing his portfolio to conform to specified targets and limits. For example, the method can be used to compare both average and bad-tail loss rates of portfolios of Baa-rated debt versus portfolios of Ba-rated debt. The resampling method exchanges the large array of assumptions required by existing parametric models with an assumption that the loss experience in the database from which assets are drawn is representative of the universe of possible experience. That assumption is false, of course, but it is possible to test the sensitivity of results to at least some violations of the assumption. Moreover, the database used in this paper is a principal source of parameter values for existing parametric models (Moody's database of bond ratings and defaults during 1970-98). ${ }^{3}$ To the extent that it fails to capture the range of likely experience, parametric models may also produce unrealistic estimates.

Although this paper's findings are likely to be useful in parametric credit risk model design and to private sector risk managers as well as regulators, for simplicity the discussion is organized by reference to the internal ratings approach to Basel Accord reform. ${ }^{4}$ To the best of my knowledge, current thinking would have such an approach involve 1) an equation or similar method of allocating capital to individual assets according to their characteristics; 2) a simple summation of such allocations to arrive at a portfolio capital requirement; and 3) perhaps some adjustments to the portfolio requirement to account for variations in portfolio size or other portfolio characteristics.

Exercises reported below focus on three questions relevant to such an architecture: 1) Which asset or portfolio characteristics should be included as variables or adjustment factors? 2) What types of behavior or phenomena should be considered in estimating the parameters of the system? and 3) Is a linear structure appropriate? That is, does a simple sum of capital allocations appropriate to homogenous pools of assets approximate well the capital required for a mixed pool

\footnotetext{
${ }^{3}$ A similar database available from S\&P is also a primary source of parameter values.

${ }^{4}$ In this paper, the desirability of prudential regulation of bank capital is taken as given.
} 
of assets?

Results imply borrower default ratings, estimates of the likely loss given default on individual assets (LGD, or one minus the recovery rate), and measures of portfolio size or granularity are important candidate variables for the regulatory formula. Default ratings appear most important, with loss rates at the $99^{\text {th }}$ percentile differing by a factor of about 60 for borrowers rated A or better relative to those rated B. Predictable differences in LGDs, for example differences for senior versus subordinated debt, also can have a first-order impact on required capital. Although increases in portfolio size beyond a certain point appear to be associated with a relatively modest reductions in risk, small portfolios are significantly riskier than larger portfolios, and thus any regulation might need to be parameterized differently for small and large banks. Moreover, differences in granularity (that is, the extent to which a large fraction of portfolio exposure is to only a few obligors) can have a material effect on risk.

One natural way of implementing an internal rating-based regulation would be to estimate the capital required for portfolios composed only of assets with each permutation of rating, expected LGD, etc. Capital for mixed portfolios would be the sum of the share of the mixed portfolio in each "bucket" times the estimated requirement for that bucket. An exercise in which capital requirements as computed by such a linear approach are compared to direct estimates of required capital for a variety of portfolio risk postures yields mixed results, but on the whole implies that the linear approximation is likely to be adequate.

A potential weakness of the internal ratings approach is that it would ignore differences in certain types of diversification across portfolios. Much of the machinery of CreditMetrics, for example, is designed to estimate differences in credit risk correlations across borrowers and the portfolio risk effects of such differences. Correlations are often presumed to be related to the industries and countries in which borrowers operate, but no consensus about values of such correlations exists. Given the lack of consensus, practitioners often use credit risk models to finetune formal or informal loan-to-one-industry or loan-to-one-region limits. Monitoring of such limits has long been a part of bank examinations in the U.S. However, if bad-tail loss rates are sensitive to modest variations in the limits, it might be necessary to build such variations into the regulatory formula, a difficult task. Fortunately, resampling exercises that vary the loan-to-one- 
industry limit for a few different sets of industry definitions yield modest differences in bad-tail loss rates. Data limitations complicate resampling analysis of diversification across countries, which intuition suggests might be more important than diversification across industries within a country. See Jackson and Perraudin (1999) and Nickell, Perraudin and Verotto (1998) for some insights about country effects, and Flannery (1989) for an analysis of incentive effects of capital regulation on portfolio choices.

In estimating the parameters of an internal-ratings-based formula, policymakers and technicians should be attentive to implications of the unpredictability of individual LGDs, to the definition of default, and to the fact that capital set to limit bank failure rates in a hypothetical average year may be much less than needed in bad years. For example, many credit risk models appeal to the law of large numbers in assuming that assets that are similarly senior (for example, with similar collateral) will have similar LGDs if a default occurs. However, LGDs can vary significantly across otherwise similar assets, and the risk that a bank will be unlucky both with respect to the number of defaults and their severity can be material, even if LGD rates and default rates are assumed to be uncorrelated.

On the whole, this paper's results indicate that if the internal-ratings approach properly accounts for all the first-order-important dimensions of credit risk, it is likely to produce regulatory capital allocations for credit risk that are reasonable approximations to economic capital allocations. However, factors in addition to those considered in this paper are also likely to be important determinants of portfolio risk, so more research is needed before final conclusions are reached. For example, this paper focuses only on losses associated with defaults and distressed restructurings and thus is most consistent with a "default mode" or standard accounting view of credit risk. However, in a mark-to-market view, both variations in borrower credit quality short of default and variations in open-market credit spreads are important determinants of changes in portfolio market value. Kiesel, Perraudin, and Taylor (1999) offer evidence that such factors may be comparable in importance to default risk.

Also probably important, but not analyzed in this paper, are the remaining maturity of assets and the proper horizon over which portfolio credit risk should be measured (see Calem (1999), Jackson and Perraudin (1999) and Kiesel, Perraudin and Taylor (1999) for some relevant 
evidence). Although a one-year analysis horizon is conventional in credit risk modeling and is used here, default-mode analyses using such a horizon unrealistically assume that a bank losing almost all its capital in a given year will either be able to recapitalize at the end of the year or will suffer no or small losses in subsequent years.

This paper's results are not meant to be estimates of the levels of capital requirements that regulators should require for any given portfolio, but rather as indicators of likely proportional differences in levels as asset and portfolio characteristics vary. The appropriate level is sensitive to a variety of assumptions, including the degree of systemic and deposit-insurer risk that regulators are willing to tolerate, and is a matter beyond the scope of this paper. ${ }^{5}$

To the extent that a reader does wish to take this paper's estimates as preliminary indicators of levels of economic capital requirements for credit risk alone, it is important to note that the most appropriate point of comparison in the current Accord is the 4 percent Tier 1 leverage ratio. Although the bad-tail loss rates reported below combine expected and unexpected losses, borrowers rated riskier than B3 are omitted from the exercises, and at least in the U.S. much of the loan loss reserve is allocated to losses associated with such borrowers. Thus, the bad-tail losses reported in tables conform most closely to those that equity capital would absorb in the U.S.

As noted, regulatory applications are emphasized in this paper's discussion, but the results are relevant for credit risk managers at banks and other financial institutions and to sponsors of collateralized debt obligations (CDOs). All such institutions make simultaneous decisions about portfolio risk, capital structure, and remaining risk to be borne by their residual claimants, and knowledge of the determinants of debt portfolio credit risk is helpful to such decisionmaking.

Section 1 describes the data, and Section 2 some details of the resampling method. Sections 3 through 9 report results, and Section 10 offers concluding comments.

${ }^{5}$ See Vojta (1973) for an early analysis of the appropriate level and structure of capital requirements. 


\subsection{Data}

Information about corporate bonds rated by Moody's, including the ratings of bonds and issuers, the identity and timing of defaults, and some other characteristics is obtained for the years 1970-98 from the April, 1999 release of Moody’s Corporate Bond Default Database. The Moody's database is a complete history of their long-term rating assignments for both U.S. and non-U.S. financial and nonfinancial firms and sovereigns (no commercial paper ratings, municipal bond ratings, or ratings of asset-backed-securities are included). In addition to the ratings of individual bonds, Moody's provides a table of issuer ratings, that is, the actual or likely rating on a senior unsecured bond for each issuer for each date the issuer had any rated bonds outstanding. All analysis is done at the issuer level and is restricted to U.S. issuers (the number of non-U.S. issuers became material only in recent years). ${ }^{6}$

A loss experience record is constructed for each issuer and year in which the issuer was rated at the start of the year. Those cases where the issuer defaulted during the year are exposedand-defaulting records, whereas those where no default occurred are counted as exposed but not defaulting. Similar to the methods of Moody's annual study of default rates by grade, the rate for any year and grade is the number of defaults divided by the total number of exposures. Cases where an issuer's rating is withdrawn during the experience year are counted as half a unit of exposure unless the issuer defaults. ${ }^{7}$

In this paper, each exposure-year record is treated as representing all exposures to the borrower. Although a given borrower may have many loans outstanding at a given bank, in the U.S. it is rare that a borrower defaults on some but not all obligations. Thus, it is conventional in

${ }^{6}$ Analysis of the impact of default probabilities versus that of LGDs on portfolio risk would be muddied by use of bond-level rating data. Moody's considers both the quality of the issuer and the terms of the indenture in rating a bond, especially terms like collateral, guarantees, or subordination provisions. In contrast, variations in issuer ratings across borrowers are more likely to be indicative of differences in the probability of issuer default because such ratings are uniformly for a senior unsecured claim.

${ }^{7}$ Carty (1996) examined rating withdrawals and found almost all to be associated with maturities and calls of bonds, not with an imminent default. Moreover, the database tracks defaults even if they occur after Moody's withdrew ratings. 
credit risk analysis to aggregate all loans to a borrower into a single exposure. Loan sizes are simulated according to the rules and purposes of each exercise, as described below.

Moody's assigns one of about 200 industry codes to each borrower. Some of the codes correspond well to conventional definitions of industries (an example is "Airlines") but some are quite narrowly focused (examples are "Hospital supplies" versus "Hospitals/nursing"). In monitoring their exposure to individual industries and in imposing limits on such exposure, most large banks use internally developed industry classifications involving a few dozen categories. To simulate such procedures, I judgmentally created two separate classification schemes that boil down Moody's 200 categories into 20 and 39 categories, respectively.

Moody's database contains some (but not complete) information on the LGDs of defaulted bonds. Because every study to date has found substantial differences between the LGD experience of loans and bonds (for example, Society of Actuaries 1998, Asarnow and Edwards 1995, and Hamilton and Carty 1999), the bond LGDs are not used in this paper. Instead, LGDs for each default are set or simulated according to the rules of each exercise, as described below.

\section{Some Details of the Resampling Method and its Implementation}

Events in the bad tail of a financial intermediary's portfolio loss distribution can cause insolvency unless the portfolio is financed entirely with equity. If it is financed partly with debt, the probability of insolvency can be reduced to a given level by choosing a capital structure with enough equity to cover the loss at the percentile of the portfolio loss distribution equal to that level. ${ }^{8}$ Estimating how capital ratios must vary to preserve a given insolvency probability as portfolio characteristics change is a matter of estimating how the portfolio loss distribution changes.

The resampling method traces out loss distributions nonparametrically. For each exercise (set of portfolio parameters), 100,000 simulated portfolios are composed by drawing randomly from the loss experience database until the specified portfolio size is reached. Draws for any single simulated portfolio are without replacement. Drawn assets are rejected for inclusion if they

${ }^{8}$ For example, if the loss rate at the $99^{\text {th }}$ percentile is 5 percent, then a 5 percent equity capital ratio will be sufficient to prevent insolvency with probability 0.99 . 
fail to satisfy the parameters for the given exercise. For example, each exercise specifies a target percentage of the portfolio to fall in each rating category. A Baa-rated asset would be rejected for inclusion if sufficient assets with that rating had already been drawn, even if the total simulated portfolio was not yet filled. Looking across simulated portfolios, all will have the same set of specified characteristics, but some will by chance include many defaulting assets and others few. Dollar loss rates are computed for each drawn portfolio, and the frequency distribution of such losses forms an estimate of the loss distribution for portfolios with the specified characteristics. For example, after rank-ordering simulated portfolios by loss rate, the loss rate for the 99,000th portfolio would be the estimated capital ratio sufficient to present insolvency with probability 0.99 for portfolios specified in the exercise.

For any given simulated portfolio (iteration), the draw is in two stages: 1) One of the 29 experience years in the database is drawn, and 2) individual loans exposed during that year are drawn until the simulated portfolio is filled. Using experience from multiple years for a given simulated portfolio would tend to understate tail loss rates because the results of different realizations of systematic economic risk factors would be unrealistically combined.

The resampling method's strength is its lack of assumptions about functional forms of distributions, parameters, and covariances among asset returns. However, when applied to the Moody's database, the method has several weaknesses. Most importantly, the period 1970-98, though long by the standards of credit risk experience databases, does not capture the full range of possible systematic events. For example, the United States did not experience a depression, and many specific industries did not experience severe distress, but both a depression and distress in heretofore untroubled industries are possibilities in the future. Thus, all tail loss rate estimates are understated in that the effects of very bad systematic events are not modeled.

In principle, parametric credit risk models can avoid this problem by specifying parameters that embody sufficiently pessimistic assumptions about future events. However, in practice, historical data is used to estimate the parameters of such models, and the Moody's and S\&P databases are principal sources of such data. In general, I recommend caution in interpreting the levels of tail loss rates estimated by any available method. In setting levels for capital regulations, policymakers should ask to see bad-tail loss rate estimates for different assumptions about the 
frequency and severity of future systematic economic events.

A general advantage of the resampling method is that the effect of realistic correlations of losses across individual assets are reflected in estimated bad-tail loss rates because such correlations are embedded in the loss experience database. However, in applications of the method, the realism of embedded correlations is limited by the features of the database being used. Major advantages of the Society of Actuaries database used in Carey (1998) are its focus on private debt instruments and its incorporation of actual LGDs for each credit risk event, so that both cross-default and default-LGD correlations typical of loans are captured. However, that database covers a relatively short time period (1986-92) and lacks information about the industry of many borrowers, limiting both the range of correlations reflected in the data and the ability to study the effect of industry diversification on bad-tail loss rates. The Moody's database is in many respects a mirror image. It covers a relatively long time period and has complete information about borrower industries, but covers only public-debt issuers and has LGD information that is not very useful for purposes of this paper. Fortunately, for exercises that are qualitatively similar here and in Carey (1998), results are usually qualitatively similar.

Because the Moody's data are at the issuer level and bond LGDs differ so much from those for loans, it is necessary to assign both loan sizes and (for defaults) LGDs to each observation rather than using values drawn from the data. To some extent, such generated data are a necessity because studying the effects of variations in portfolio granularity and LGD properties involves perturbing those characteristics. However, to make the base-case data as realistic as possible, both loan sizes and LGDs are assigned randomly such that the distribution of their values closely matches distributions that are realistic for private debt portfolios. Except as otherwise noted, the simulated distribution of individual LGDs matches closely the distribution reported in Society of Actuaries (1998). ${ }^{9}$ Except where fixed identical loan sizes are simulated, loan sizes are set as fractions of total simulated portfolio dollar value to match the distribution of

${ }^{9}$ LGDs are assumed uncorrelated with default rates (for example, simulated LGDs are not systematically different for defaults in recession and nonrecession years). This assumption of independence is common in the credit risk modeling literature, and is not inconsistent with the limited available empirical evidence, but studies identifying the degree of any correlation are needed. 
fractions for an actual large U.S. bank. In most simulations reported below, about 40 percent of total dollar exposure is associated with the largest 10 percent of individual exposures. Such skewness of sizes is not atypical: I have inspected loan size distributions for a variety of large financial institutions and they typically involve a significant concentration of assets.

The resampling method is data-intensive in that it requires that the database have considerably more loss experience records with a given set of characteristics than are required to populate any given drawn portfolio. For example, if a portfolio of $500 \mathrm{Ba}$-rated loans is to be simulated and there are only 500 Ba-rated loans in the database for each year, the estimated loss distribution will collapse to the overall average loss rate because all the loans will be drawn for each iteration. Experiments indicate that numbers of observations in database cells must be at least five or six times larger than numbers in simulated portfolio cells. The Moody's database does not satisfy this requirement for virtually all of the exercises reported in this paper.

I address the problem by replicating the base data for each grade a sufficient number of times. For example, to ensure that there are enough Baa loans in every year, for most exercises I create a single replica of each Baa loss experience record in each year. Replicas are identical to base records except that a different borrower ID number is assigned, a different loan dollar size is assigned (as described previously), and if it is a default a different LGD is assigned (as described previously). For any given exercise, the replication factors are held constant across the different permutations of the exercise.

Such replication represents an intermediate case between sampling from the data with replacement and without replacement. It may seem problematic in that with replication the same defaulting borrower can be drawn twice into the same portfolio, but such a view is not quite correct. In the exercises of this paper, borrower identity is unimportant---each observation is an exposure to a different simulated borrower, and each borrower is simply a bundle of rating, industry, and default-nondefault characteristics. Replication preserves exactly the proportions of defaulting and nondefaulting borrowers in each grade and industry in each year, and also the fraction of exposures in each industry.

Different degrees of replication may, however, affect the levels of estimated bad tail loss rates, and thus in some views of credit risk replication can be thought of as affecting the cross- 
default correlations embedded in the data. To see the effect, imagine that in Moody's database only two borrowers defaulted in a given grade and year. When simulating a portfolio of 100 loans by drawing without replacement, the maximum estimated default rate for that grade and year is 2 percent---the bad tail is truncated beyond that point because in building a given simulated portfolio if both borrowers happen to be drawn it is certain that remaining loans drawn into the portfolio will be nondefaulters. This seems unrealistic---there are always more bad loans to be made---and thus drawing without replacement from any actual database seems likely to understate true bad-tail loss rates. That is, as noted previously, the correlations embedded in any actual finite database, because they represent only a portion of the possible range of experience, seem likely to understate the true correlations. Going to the other extreme, if draws are with replacement, it is always be possible to draw another simulated default into a simulated portfolio, and indeed the likelihood of doing so is unaffected by the outcome of any previous draws. This also seems a bit unrealistic. The method most likely to deliver accurate estimates of the levels of bad-tail loss rates---with replacement, without, or some intermediate method implemented by some degree of replication---is a question for future research. For the purposes of this paper, however, results of interest are qualitatively insensitive to the degree of replication that is applied.

\section{Results for a Base Case}

Table 1 presents the parameters of the base case. Subsequent exercises vary one of the parameters while holding the others constant at base-case values unless otherwise noted. The base portfolio has $\$ 5$ billion of commercial loans with sizes that vary in a manner similar to that of an actual large bank, as described previously. The number of loans in the portfolio is not fixed, but the parameterization of the loan size distribution keeps the number close to 500. In a few exercises I fix the number of loans and let the portfolio dollar total float, but that requires enforcement of loan-to-one-borrower and loan-to-one-industry limits in terms of fractions of the number of loans rather than fractions of the dollar total, which is unintuitive. However, results are qualitatively similar regardless of whether numbers or dollars are fixed.

The loan-to-one-borrower limit is set at 3 percent of portfolio dollar size, while the loanto-one-industry limit is 5 percent of portfolio size and is implemented using the judgmentally 
developed 39-industry classification scheme described previously. All loans are presumed to be senior, only actual defaults appearing in the database are treated as credit risk events, and the LGDs for those defaults are generated such that their distribution matches the distribution for senior loan default LGDs in Society of Actuaries (1998). The distribution of portfolio dollars across ratings conforms to the average distribution for large U.S. banks reported in Treacy and Carey (1998).

The first row of Table 2 reports results for the base case. The mean or expected loss rate is 0.63 percent, whereas loss rates at the $95^{\text {th }}, 99^{\text {th }}, 99.5$ th, and 99.9 th percentiles of the distribution are $1.87,2.71,3.04$, and 3.87 percent, respectively. ${ }^{10}$ Clearly loss rates rise significantly with the percentile, for example implying that considerably more capital is required to prevent insolvency in 999 of 1000 portfolio-years than in 950 of 1000 experience years. The mean loss rate of 0.63 percent is less than the 1 percent long-run average C\&I loan chargeoff rate for U.S. banks, but as noted issuers rated riskier than B3 are omitted from the exercises, and the set of credit events includes defaults but no negotiated restructurings. Loans to issuers riskier than B3 would generally be considered "classified" assets on U.S. bank balance sheets. A significant share of real-world average or expected losses is associated with such loans and with negotiated restructurings, so their inclusion in simulations would move the mean estimated loss rate much closer to 1 percent. $^{11}$

The second through fourth rows of Table 2 show that results are little affected when the replication factor for each grade is doubled, set to 30 for all grades, or set to 80 for all grades, respectively. Estimated loss rates at the different percentiles differ from base values by from two to nine basis points, representing at most a 0.03 percent proportional change in the base case loss rate. As noted, previously, although in principle the appropriate degree of replication is uncertain, in practice results appear insensitive to variations in the replication factors.

${ }^{10}$ For readers accustomed to unexpected loss rates, those would simply be the loss rates at the far percentiles minus the mean loss rate.

${ }^{11}$ No significance should be attached to the fact that the level of the loss rate at the 99.9th percentile is close to the 4 percent Tier 1 capital ratio of the current Basel Accord. 


\section{Results When All Loans Are in One Grade}

Table 3 presents results for portfolios composed entirely of assets rated A or better, Baa, $\mathrm{Ba}$, and $\mathrm{B}$, respectively, and for comparison results for base case parameters when the larger replication factors used in this exercise are applied. Focusing on the mean and $99^{\text {th }}$ percentile loss rates, both the mean and bad-tail rates are near zero for assets rated A or better, reflecting the fact that very few issuers with such ratings defaulted over a one-year horizon during the years since 1970. Looking down the grades, the expected loss rate rises by a factor of about 700 between the $\mathrm{A}$ and $\mathrm{B}$ categories while the $99^{\text {th }}$ percentile loss rate rises by a factor of about 60 . Tail rates for the investment grades (Baa and above) are far below that for the base case. Straying for a moment into interpretation of levels of results, investment-grade tail rates are also far below current regulatory capital requirements, which is evidence of banks' large incentives to move such loans off the balance sheet. B-rated bad tail loss rates are well above those of the base case and well above current Tier 1 regulatory requirements, implying that current regulations do not require enough capital for relatively risky loans. In the absence of regulatory reform, the share of risky loans in bank portfolios is thus likely to increase.

Overall, it seems clear from the results in Table 3 that ratings are an important indicator of a loan's contribution to bad-tail risk and thus of marginal economic capital requirements. Readers accustomed to the findings of standard portfolio theory may find this an uncomfortable result (that indicators of stand-alone asset risk or volatility are highly correlated with portfolio returns). As noted previously, models which account for the differences between debt and equity imply such a relationship (see Zhou 1997 for an example). Moreover, ratings may also be indicators of the degree of correlation of default risk with systematic economic factors such as the business cycle. In descriptions of their methodologies, the rating agencies state that firms in cyclically volatile industries are more likely to be assigned riskier ratings, other things equal.

\section{Seniority is Important}

Although LGDs vary widely across individual defaults and restructurings, with senior secured credit events sometimes imposing a total loss and junior subordinated credit events sometimes imposing no loss, on average the values of LGDs differ with the priority of the debt 
and the nature of the credit event. For bank loans, which are generally senior or secured, Carty et al. (1998) find that the mean LGD for senior unsecured bank loans to bankrupt firms is 21 percent, whereas it is 13 percent for secured loans. Carty and Lieberman (1996) also report statistics implying that collateral on average is associated with a 10 percentage point difference in LGDs. Asarnow and Edwards (1995) find a 35 percent LGD for C\&I loans without distinguishing priority. For bonds, Altman, Waldman and Kane (1996) find mean LGDs of about 50 percent for senior secured, about 60 percent for senior unsecured, and roughly 80 percent for subordinated debt. For private placements, Society of Actuaries (1998) reports mean LGDs of 20 and 44 percent for restructurings and defaults, respectively, and about a 15 percentage point difference between the mean LGDs of senior and subordinated defaults. The broad range of values found by the different studies reflects not only different types of debt and different samples but also different methods of measurement.

Priority differs across instruments in bank portfolios, raising the possibility of predictable differences in both average and bad-tail loss rates across portfolios. To obtain evidence about the importance of seniority-related asset characteristics to capital allocations, I vary the proportion of simulated portfolio assets that are subordinated, using two sets of LGD assumptions. Table 4 reports results when the percentage of subordinated loans in simulated portfolios varies between 0 and 80 percent and when LGDs for individual credit events have simulated values that mimic the event-type and seniority-specific distributions in Society of Actuaries (1998) (means are 44 and 63 percent for senior and subordinated defaults, and 22 and 24 percent for senior and subordinated restructurings). Simulated restructurings are added in proportion to the defaults already in the data, as described in more detail in Section 9.1. Here the only role of the restructurings is to provide a platform to allow differences between LGDs on defaults and restructurings to be material to results. In Table 4, both mean and bad-tail loss rates increase by about 20 to 25 percent from the 0 to the 80 percent subordinated case, amounting to about a full percentage point difference in loss rates at the highest reported percentiles.

Table 5 shows results for an exercise in which simulated LGDs are set to identical values for all credit events of a given type and seniority (10 and 50 percent for senior and subordinated defaults, respectively, and 5 and 20 percent for senior and subordinated restructurings). The 
values were chosen to demonstrate the effects of larger differences in asset-type-related LGDs than are embedded in Table 4's exercises. Unsurprisingly, the effect of varying the subordinated fraction is larger, with loss rates at the $99^{\text {th }}$ percentile increasing by a factor of four.

If Carty et al.'s (1998) evidence that collateral yields only about a 10 percentage point improvement in average LGDs reflects reality, and if a secured-unsecured distinction is the only one relevant for bank loan portfolios, then the differences in loss rates shown in Tables 4 and 5 overstate somewhat the possible distortions of ignoring seniority in capital regulations. However, many bankers believe that type of collateral is as important as presence of collateral, positing large differences in expected LGDs across types. Moreover, banking organizations increasingly are investing in the full range of capital market instruments, including unsecured junior subordinated debt, for which LGDs are on average far worse than those of secured loans. Thus, results in Tables 4 and 5 probably understate the importance to capital of variations in the seniority of portfolio investments. Overall, it appears that a failure to include in regulatory capital requirements a sensitivity to LGD-related asset characteristics might be quite distortionary.

\section{Portfolio Granularity is Important}

Standard portfolio theory, as applied to equity portfolios, implies that portfolio risk becomes almost insensitive to portfolio size beyond a rather modest number of assets. However, as noted previously, debt portfolios are much harder to diversify than equity portfolios. Moreover, actual banks' loan portfolios tend to contain some loans that are rather large in dollar amount relative to the portfolio dollar size. Intuition suggests that for such portfolios the performance of a relative handful of loans can have a material effect on loss rates.

Full-scale credit risk models, such as CreditMetrics, handle variations in portfolio granularity naturally because individual exposure sizes enter the calculations, but differences in granularity are a bit more problematic for the internal-ratings approach to capital regulation. That approach would place assets with similar ratings, expected LGDs, etc. into groups or "buckets," with an implicit presumption that each bucket contains a large number of relatively small loans. However, it seems likely that an internal-ratings approach could approximate the effects of differences in portfolio granularity across banks by applying a granularity adjustment factor to 
each bucket (see Gordy 2000b for an example).

Table 6 displays effects of varying both the number of loans in simulated portfolios and the distribution of loan sizes. For these exercises, the size of each simulated portfolio is controlled such that the number of loans is the same for each while the dollar totals vary somewhat around target amounts. Loan-to-one industry and loan-to-one-borrower limits are enforced in terms of the number of assets and also are roughly enforced in terms of fractions of portfolio dollar amounts.

The first row shows results for parameters similar to those of the usual base case, which features a distribution of loan sizes typical of an actual large bank, whereas the second row shows results when each of the 500 portfolio loans are the same dollar size. Equalizing loan sizes reduces the $99^{\text {th }}$ percentile loss rate by about 20 percent, implying that differences in granularity across banks may have significant implications for the economic capital they require for credit risk.

The third through fifth rows of Table 6 feature the usual random loan sizes but different numbers of loans. When the number is reduced to 100 loans, bad-tail loss rates increase by 50 percent relative to those in the first row. When the number is increased to 1000 or 2000 loans, bad tail rates are modestly smaller than those in the first row, by as much as 10 percent or so. These results suggest that though differences in numbers of loans across very large banks may not have much impact on portfolio credit risk, differences in size distributions might. Moreover, if an internal ratings approach to regulatory capital is to be applied to small banks as well as large banks, some adjustment of capital requirements for their much smaller portfolios probably is appropriate. $^{12}$

Loan-to-one-borrower size limits are written into formal U.S. bank regulations and internal limits tighter than those of the regulation are part of the policies of every major U.S. bank. Table 7 provides some additional insight into the effects of variations in portfolio

${ }^{12}$ In passing, note that granularity differences have essentially no effect on mean or expected losses. They only influence bad-tail loss rates. A practical interpretation of this regularity is that a bank with a concentrated portfolio can experience no problems for many years, but a surprise can more easily be fatal than for a bank with a fine-grained portfolio. 
granularity by varying the tightness of the loan-to-one-borrower limit that is routinely imposed as part of this paper's exercises. The third row has results for the 3 percent limit that is standard in this paper. Looking up the rows, a five percent limit has essentially no effect. No limit at all also does not change loss rates except at the 99.9th percentile, where the effect is a huge increase of more than three percentage points. This pattern is reflective of the fact that the portfolio of the actual bank upon which simulated loan sizes are based has only a few exposures larger than 1 percent of the portfolio, but those are much larger. Thus, in simulations, it is rare that the large loan size is assigned and doubly rare that it is assigned to a defaulting asset. With no oneborrower limit at all, huge loans are not screened out of the portfolio, and even though such loans rarely default their presence is enough to have a major impact on the far tail of the portfolio loss distribution.

Looking farther down the table, tighter loan-to-one-borrower limits have noticeable effects on bad-tail loss rates, especially at the 99.9th percentile. The lesson of these results is that loans which are large relative to portfolio size have a material effect on portfolio risk and economic capital requirements. For banks that use sophisticated credit risk models in making operating decisions, a very tight loan-to-one-borrower limit may not be needed, as such banks are likely to properly allocate more capital against such loans than against smaller loans and to adust loan pricing accordingly. However, other banks might be well served by very tight internal loan to one borrower limits, regardless of the state of regulations.

\section{Industry of the Borrower Does Not Appear Crucial}

Cross-asset default correlations are a central focus of many credit risk models. Though such correlations cannot be measured directly with any confidence with available data, several measurement strategies are employed by practitioners. ${ }^{13}$ Some use contingent claim modeling techniques to extract information from equity price correlations, but perhaps more common are methods that base estimated correlations on the industry and country of the borrower plus

${ }^{13}$ McAllister and Mingo (1996) argue that tens of thousands of individual borrower loss experience observations covering many years are required for confident direct measurement of default correlations. 
aggregate information about the performance of the industries and countries.

Traditional credit risk managers have for generations employed a simpler method of appraising and limiting the impact of correlated exposures on portfolio risk: they impose limits on the fraction of portfolio exposure to borrowers in any given industry or country. The limits usually do not vary by industry and are only somewhat specific to different regions of the world, reflecting the fact that a long period of untroubled performance by a given industry or country is no guarantee of an untroubled future.

As a practical matter, a regulatory capital regime cannot include limits or capital charges specific to a given industry (and perhaps not to a given country). In addition to the difficulty of estimating the values of such limits or charges, their imposition would be seen politically as a form of government-enforced credit rationing. Moreover, inclusion of such limits as part of regulation would be technically challenging because of the lack of a single industry coding scheme universally recognized as appropriate for all portfolios.

However, limits on exposure to any single industry regardless of identity probably should be a part of supervision, where judgment can be applied in evaluating industry groupings. Such limits have been a part of banking supervision in the U.S. for many years in that examiners criticize banks having portfolios that they believe are too concentrated. However, to my knowledge, examiners base their reviews on intuition and a sense of standard industry practice. To my knowledge, no empirical evidence about the implications for bad-tail loss rates of different industry limits has appeared.

Analysis of industry limits is not entirely mechanical in that it is possible that the details of the industry classification scheme might affect results. Tables 8 and 9 present evidence for different limits using the 20-industry and 39-industry schemes described previously. Results are qualitatively similar when Moody's 200 industry codes are used directly (not shown in tables). Focusing on Table 8, the usual base case, which involves a 5 percent loan-to-one-industry limit, is reported in the last row. Raising the limit to 10 percent increases the loss rate at the $99^{\text {th }}$ percentile by about seven percent, from 2.75 to 2.95 percent. Imposing no limit at all raises the rate at the $99^{\text {th }}$ percentile modestly, to 3.11 percent. Table 9 displays similar effects of variations in limits when the 20-industry classification scheme is used. 
Variations in loan-to-one-industry limits have relatively modest effects because defaults in any given year in the Moody's data tend to be spread across several different industries, with the largest number of defaults in each industry being around 10 in any of my classifications. Even where a tight limit screens some exposure out of a relatively high-default industry in a given year, there are enough defaults in the same year in other industries to make possible large losses if the lender happens to invest in the wrong borrowers. Moreover, the resampling engine naturally tends to spread exposure across a number of industries (so the results in Tables 8 and 9 do not reflect loss rates if simulated portfolios were forced to include only loans to a single industry).

I believe the results imply that for the moment cross-industry correlations can be safely ignored in formal capital regulation for straight loan portfolios. Although supervisors and bank managers should be attentive to concentrations of loans to firms in a single industry, at this time there is little empirical basis for specifying precise loan-to-one-industry limits in regulation. However, for structured products like credit derivatives or subordinated tranches of CLOs, considerations of cross-industry diversification probably are significant. Moreover, improvements in credit risk measurement may in the future provide an ability to specify loan limits or tradeoffs among industries with confidence. Limits on country exposure may be measureable now, but data limitations led me to forego attempting measurement in this paper. ${ }^{14}$

\section{The Internal Rating Approach's Linear Approximation Might Be Good Enough for Loans}

As noted previously, the internal ratings approach to capital regulation involves an assumption of linearity or perfect correlation across different permutations of key dimensions of credit risk. That is, capital would be computed for each asset or subportfolio according to its characteristics and such allocations would be summed to obtain a total portfolio capital requirement. Gordy (2000b) shows that such a setup presumes that the risk of assets in all buckets is driven by a single systematic risk factor, e.g. that mixing grades in a portfolio yields no diversification benefits.

${ }^{14}$ Effects of different country limits are difficult to analyze with the Moody's data because substantial numbers of non-U.S. obligors have appeared in the data only in recent years. 
Evidence on the accuracy of the linear approximation is provided by estimating loss rates at the $99^{\text {th }}$ percentile for portfolios with various mixtures of loans across grades, both directly and using the linear approximation. Only the mix of grades is varied, with all other parameters fixed at base-case values. Fractions of portfolio dollars in each of the grades A or better, Baa, Ba, and $\mathrm{B}$ are varied in 20 percent increments, producing 56 different permutations (e.g., 100,0,0,0; $80,0,0,20 ; 80,0,20,0$; etc.). The $99^{\text {th }}$ percentile loss rate is estimated directly for each permutation. The linear approximation is computed by multiplying the percentage in each grade times the $99^{\text {th }}$ percentile loss rate for a portfolio composed only of loans in that grade.

Differences in direct and approximated capital requirements are expressed as a percentage of the direct estimates in Figure 2 and in absolute terms in Figure 3, one bar per permutation. Permutations are sorted along the horizontal axis according to the fraction of the portfolio in the A grades, then the fractions $\mathrm{Baa}$ and $\mathrm{Ba}$. For example, the permutation with 80 percent of loans rated $\mathrm{A}$ or better and 20 percent rated $\mathrm{B}$, the fourth bar from the right, features an absolute error of about 0.6 percentage points of capital, with the approximated requirement of 1.4 percent being about 30 percent below the directly estimated requirement of about 2 percent.

Both percentage and absolute errors generally grow with the fraction in the A grades, and the approximation generally understates the directly estimated requirement. The percentage error can be large, ranging up to 40 percent. However, the absolute errors are modest, almost always less than 0.5 percentage points of capital.

On the whole, I view these results as supportive of the adequacy of the linear approximation. The largest percentage errors arise for high-grade portfolios, and capital requirements are particularly difficult to estimate for such portfolios. At a one-year horizon, defaults by borrowers in the Aaa, Aa, and A grades are extremely rare and their timing relative to the business cycle is idiosyncratic across databases. ${ }^{15}$ Thus, the imprecision of directly estimated tail loss rates for such portfolios may be similar to that of the linear approximation.

${ }^{15}$ A caveat is that results of a similar exercise using Society of Actuaries (1998) data, though qualitatively similar, produced somewhat larger approximation errors that indicate the approximation would generally overstate capital requirements. This is symptomatic of the difficulty of measuring diversification effects. 


\section{Some Factors to Be Considered in Parameterizing an Internal-Ratings-Based Regulatory Regime}

Several factors that may not be obvious must be taken into account in the parameterization of a credit risk model or regulatory capital regime. Some such factors may appear to be mostly of interest to technicians, but policy decisions that influence their handling can have a large effect on estimated economic capital allocations and thus regulatory requirements.

\subsection{The Definition of Default is Important}

One such matter is the definition of "default" to be used in estimating and accounting for credit losses. The niceties of the definition are less important in mark-to-market models, but the banking industry's strong past preference for historical cost measures may make adoption of mark-to-market approaches politically infeasible. If that is the case, the set of credit risk events to be counted as loss-causing events and against which regulatory capital is required is material (and must be reasonably standardized across banks). Most would agree that the payment defaults which are recorded in the Moody's database should be included as loss events. Uncommon in the bond market and thus not in Moody's database are distressed restructurings, in which the payment terms of the original debt contract are altered in negotiations between borrower and lender. ${ }^{16}$ Although LGDs for restructurings are smaller on average than those for defaults, restructurings frequently impose losses on banks, who agree to them because the alternative may be bankruptcy and its associated costs. Evidence in Society of Actuaries (1998) shows that restructurings are common in private debt markets and represent a significant share of lenders' total credit losses over time: 127 of 566 credit risk events in that study were restructurings, with a 21 percent mean LGD versus a 45 percent mean LGD for defaults.

I simulate the effect of including restructurings in the definition of default by randomly creating restructuring events in the Moody's data for otherwise nondefaulting experience records. Two exercises are conducted. In the first case, about one restructuring is created for every three

${ }^{16}$ Moody's database treats distressed exchanges as defaults. Such exchanges differ from restructurings in that exchanges are usually coercive take-it-or-leave-it offers by the issuer whereas restructurings are negotiated. 
defaults in each year and grade of the base data. In the second case, the restructuring rate is still proportional to defaults by year and grade, but the rate is twice as high for below-investmentgrade borrowers than investment-grade borrowers, resulting in creation of about one restructuring for every two defaults. Severities for the restructurings are simulated to conform to the distribution of restructuring severities in Society of Actuaries (1998), whereas those for defaults conform to the distribution for defaults in that study. ${ }^{17}$

Results for the two exercises appear in Table 10. Unsurprisingly, including restructurings raises both mean and tail loss rates, with proportional changes being in the 10 to 25 percent range and larger for the second exercise than the first. Although the impact of including restructurings in the definition of default is modest relative to the impact of ratings on the bad tail, the effects are economically significant. Thus, regulators and bankers should be attentive to the definition of default in setting up their systems. ${ }^{18}$

\subsection{That LGDs Vary Across Defaults Is Material}

A common assumption in credit risk modeling is that expected LGDs for individual defaults can safely be set to the average value of such LGDs for assets of similar seniority. An appeal is made to the law of large numbers: Although individual-asset LGDs vary widely, annual defaults for any large-bank portfolio are likely to number in the tens or hundreds, and thus for defaults as a whole the LGD will collapse to a value near the population mean. The flaw in this argument is that real portfolios are not completely fine-grained: Even with tens of thousands of assets in the portfolio, the largest 50 or 100 loans usually account for a significant fraction of total dollar exposure. If a few of these large loans default (an event which usually is associated with a portfolio loss rate far out in the bad tail), the idiosyncratic variation in realized LGDs for those few assets can have a material effect on the portfolio loss rate.

Table 11 demonstrates the importance of the fixed versus variable LGD assumption. The first row reflects base case parameters except that simulated restructurings are included, as

\footnotetext{
${ }^{17}$ No controls on the industry of restructured loans are imposed.

${ }^{18}$ The effect on loss rates is more modest than if similar numbers of defaults were added to the data because LGDs for restructurings are smaller.
} 
described in the previous subsection. As noted previously, simulated LGDs vary across defaults in a manner similar to the distributions in Society of Actuaries (1998). In the second row, LGDs are fixed at the sample average rates for each type of credit event (44 percent for defaults and 22 percent for restructurings). Although the fixed-LGD assumption has little effect at the $95^{\text {th }}$ percentile, it materially reduces the estimated loss rate at the 99.9th percentile, by about 15 percent. Thus, in parameterizing an internal ratings-based capital regulatory regime, if the projected bank failure rate regulators are willing to tolerate is quite low (corresponding to a percentile very far out in the bad tail), it will be important to take idiosyncratic variation of LGDs into account.

\subsection{Bad-Year Experience Strongly Influences the Tail Loss Rates}

It is conventional in credit risk modeling to implicitly express the rate of bad tail events in terms of the likelihood of such events in an average year, that is, as though such events might occur at any time. While bad-tail events are indeed possible at any time, intuition suggests that they are far more likely to occur during times of general economic distress. Estimating portfolio loss distributions by equally weighting events in each database year, as is done throughout this paper, tends to understate bad tail loss rates. In choosing a level of capital requirements, policymakers must decide whether they wish the level of soundness they choose to apply for the average year or for bad years in particular. This section provides a sense of the difference in bad tail loss rates (and thus capital requirements) associated with such a decision by comparing tail rates when all experience years in the Moody's database are used in simulations with rates when only good years or bad years are used. Bad years include the five years of highest overall average default rates in the data, which are 1970, 1986, and 1989-91, whereas good years are all others during the period 1970-98.

The first three rows of Table 12 show loss rates for the usual base-case distribution of loans across grades when all years are equally weighted in the simulations and when only good years versus only bad years are used. Both mean and tail loss rates are sharply higher in the bad years than in the good years. The patterns imply that to achieve loss protection at the $99^{\text {th }}$ percentile, capital ratios in the bad years must be about 175 percent of those needed in the good years, and about 130 percent of those estimated to be required when all years are equally 
weighted. Looked at another way, a policymaker choosing to require capital to protect at the $99^{\text {th }}$ percentile estimated with all years equally weighted, and thus requiring about a 2.7 percent equity capital ratio for the typical large bank, would in bad years be likely to experience a large bank failure rate of about 5 in 100, whereas in good years the failure rate would be far less than one in 100 , more like one or two in 1000 .

The remaining four rows of Table 12 display good-year versus bad-year loss rates for portfolios composed of purely investment-grade loans versus those composed only of belowinvestment-grade loans. ${ }^{19}$ Tail loss rates are sharply higher in the bad years than in the good for both types of portfolio, but the effect is somewhat more pronounced in the case of the investmentgrade portfolio. This is a bit of a surprise, as Carey (1998) found that investment-grade privatedebt portfolio bad-tail loss rates were rather insensitive to good-year versus bad-year distinctions. The difference arises because two of the three defaults of issuers rated A or better appearing in the Moody's data happened to occur in 1989 (a bad year generally), and Baa defaults were unusually high in 1986. In the Society of Actuaries data, investment grade defaults tend to occur during relatively good years. This difference in results points to the difficulty of reliably parameterizing credit risk models for the investment grades. For investment grade borrowers, defaults are small in number and their patterns are somewhat idiosyncratic to particular databases.

\section{Concluding Remarks}

The evidence presented in this paper implies that differences across assets in ratings and seniority (expected LGDs) and differences in granularity across portfolios are important influences on differences in portfolio credit risk. Bank capital regulations should take proper account of such differences or risk a continuation of large-scale capital arbitrage. Important but not widely understood considerations in determining the level of regulatory capital requirements are the definition of loss-causing credit risk events, the variability of LGDs across such events, and the extent to which regulators wish to limit failure rates in bad years or in a hypothetical average year.

On the whole, the results imply that for the commercial loan portfolios of large U.S.

${ }^{19}$ For the former, 40 percent of loans are rated $\mathrm{A}$ or better and 60 percent Baa, whereas for the junk exercises 70 percent at $\mathrm{Ba}$ and 30 percent are rated $\mathrm{B}$. 
banks, the internal ratings approach now under consideration by the Basel Supervisors Committee could adequately approximate the capital allocations likely to be produced by a full models approach. However, a number of caveats apply:

- $\quad$ More explicit modeling of correlation and other effects than appears in the internal ratings approach may be needed for structured-finance exposures such as credit derivatives.

- $\quad$ The credit risk properties of consumer loans, non-U.S. commercial loans, and other types of exposures may differ from those displayed in this paper.

- $\quad$ The data in this paper represent a mixture of loan and bond loss experience, but there is evidence that loan and bond experience differs (Society of Actuaries 1998 and Altman and Suggitt 2000).

- $\quad$ The results in this paper are most representative of the risks associated with a wellmanaged bank or portfolio. A poorly managed institution, especially one unable to provide reliable ratings of individual assets or other risk-relevant information, may pose bad-tail risks many times larger than those presented here.

- $\quad$ Regulatory capital must account for risks other than credit, such as operational risks.

- $\quad$ The remaining maturity of an asset may be an important determinant of its contribution to portfolio credit risk. However, maturity effects are intimately related to the time horizon of analysis and the choice between mark-to-market and default-mode analysis. Research on these matters is needed.

- Regulatory choices concerning the definition of capital and the soundness standard to be used will have material effects on the safety-and-soundness achieved by any new regulation.

Many other considerations are also important to design of an appropriate regulatory capital standard.

Taken as given in this paper is the desirability of prudential regulation and also the necessity of supervision adequate to ensure that such regulations are implemented properly. However, even in the absence of capital regulation, the results in this paper are useful to bank examiners, bank investors, risk managers, and asset-backed security designers. All such individuals must evaluate the credit risk embedded in debt portfolios and thus are aided by an understanding of the factors that influence portfolio credit risk. 


\section{References}

Altman, Edward I., and Anthony Saunders, 1998, Credit risk measurement: Developments over the last 20 years, Journal of Banking and Finance.

Altman, Edward I., and Heather Suggitt, 2000, Default rates in the syndicated bank loan market: A mortality analysis, Journal of Banking and Finance 24, 229-253.

Altman, Edward I., Robert A. Waldman and Christopher P. Kane, 1996, Recoveries on defaulted bonds: By industry and debt seniority, Working paper, Salomon Brothers High Yield Research.

Asarnow, Elliot, and David Edwards, 1995, Measuring loss on defaulted bank loans: A 24-year study, The Journal of Commercial Lending 77, 11-23.

Basel Committee on Banking Supervision, 1999, A new capital adequacy framework (Basel, Switzerland: Bank for International Settlements), June 3.

Calem, Paul, 1999, The relationship between maturity composition and credit loss exposure for a loan pool, Internal memorandum, Federal Reserve Board.

Carey, Mark, 1998, Credit risk in private debt portfolios, Journal of Finance 53:4, 1363-1387.

Carty, Lea V., 1996, An empirical investigation of default risk dynamics, Ph.D dissertation, Columbia University.

Carty, Lea V., David T. Hamilton, Sean C. Keenan, Adam Moss, Michael Mulvaney, Tom Marshella and M.G. Subhas, 1998, Bankrupt bank loan recoveries, Special Comment, Moody's Investors Service, June.

Carty, Lea V., and Dana Lieberman, 1996, Defaulted bank loan recoveries, Special Report, Moody's Investors Service, November.

Duffie, Darrel, and David Lando, 1999, Term structures of credit spreads with incomplete accounting information, Working paper, University of Copenhagen.

Flannery, Mark J., 1989, Capital regulation and insured banks' choice of individual loan default risks, Journal of Monetary Economics 24, 235-258.

Gordy, Michael B., 2000a, A comparative anatomy of credit risk models, Journal of Banking and Finance 24, 119-149. 
Gordy, Michael B., 2000b, Credit VaR models and risk-bucket capital rules: A reconciliation, Working paper, Federal Reserve Board, March.

Gupton, Greg M., Christopher C. Finger, and Mickey Bhatia, 1997, CreditMetrics - technical document, (New York: J.P. Morgan), www.jpmorgan.com.

Hamilton, David T., and Lea V. Carty, 1999, Debt recoveries for corporate bankruptcies, Special Comment, Moody's Investors Service, June.

Jackson, Patricia, and William Perraudin, 1999, The nature of credit risk: The effect of maturity, type of obligor, and country of domicile, Financial Stability Review (London: Bank of England), November, 128-140.

Kiesel, Rudiger, William Perraudin, and Alex Taylor, 1999, The structure of credit risk, Working Paper, Birkbeck College.

McAllister, Patrick H., and John J. Mingo, 1996, Bank capital requirements for securitized loan portfolios, Journal of Banking and Finance 20, 1381-1405.

Mingo, John, 1998, Policy implications of the Federal Reserve study of credit risk models at major U.S. banking institutions, Journal of Banking and Finance 24, 15-33.

Nickell, Pamela, William Perraudin, and Simone Varotto, 1998, Stability of rating transitions, Working paper, Bank of England, December.

Nickell, Pamela, William Perraudin, and Simone Varotto, 1999, Ratings- versus equity-based credit risk modeling: An empirical analysis, Working paper, Bank of England, July.

Ong, Michael K., 1999, Internal credit risk models: Capital allocation and performance measurement (London: Risk Books).

Saunders, Anthony, 1999, Credit risk measurement (New York: Wiley).

Society of Actuaries, 1998, 1986-94 Credit risk loss experience study: private placement bonds (Schaumberg, IL).

Treacy, William F., and Mark Carey, 1998, Credit risk rating at large U.S. banks, in Federal Reserve Bulletin 84, November.

Vojta, George J., 1973, Bank capital adequacy (New York: Citicorp).

Zhou, Chunsheng, 1997, Default correlation: an analytical result, Working paper (Federal Reserve Board: FEDS paper 1997-27). 


\section{Table 1. Parameters of Base Case}

Simulated portfolios and resampling exercises have the characteristics described in this table for the base case, and for all other cases unless otherwise noted.

\begin{tabular}{|c|c|c|}
\hline Parameter & Value & Comment \\
\hline Experience years included & $1970-98$ & Equally weighted \\
\hline Portfolio size criterion & Dollar limit of $\$ 5$ billion & \\
\hline Loan sizes & Mimic actual bank distbn. & Mean is near $\$ 10$ million \\
\hline Number of portfolio loans & Floats & But close to 500 \\
\hline Loan to one borrower limit & 3 percent of portfolio size & \\
\hline Industry classification type & Carey 39 industries & \\
\hline Loan to one industry limit & 5 percent of portfolio size & \\
\hline Fraction loans senior & $100 \%$ & \\
\hline Included credit events & Only actual defaults & \\
\hline LGD specification & $\begin{array}{l}\text { Mimic Society of Actuaries } \\
\text { (1998) distribution for senior } \\
\text { loans. }\end{array}$ & Mean is 37 percent \\
\hline Fraction rated A or better & $20 \%$ & \multirow{4}{*}{$\begin{array}{l}\text { Fractions are representative } \\
\text { of the average of large U.S. } \\
\text { banks (close to mean shares } \\
\text { of dollar outstandings } \\
\text { reported in Treacy and Carey } \\
\text { 1998). }\end{array}$} \\
\hline Fraction rated Baa & $30 \%$ & \\
\hline Fraction rated $\mathrm{Ba}$ & $35 \%$ & \\
\hline Fraction rated $\mathrm{B}$ & $15 \%$ & \\
\hline Replications each grade & $\mathrm{As}=2, \mathrm{Baa}=3, \mathrm{Ba}=5, \mathrm{~B}=15$ & \\
\hline Number of iterations & 100,000 & \\
\hline
\end{tabular}


Table 2. Average and Bad-Tail Loss Rates for Base Case

The first row reports loss rates for the base case, the parameters of which are given in Table 1. Results in remaining rows are for the same parameters except that the number of replications of loans in each year and grade is increased. Loss rates at high percentiles are total loss rates; unexpected loss rates at such percentiles are the total rate less the mean or expected rate as reported.

\begin{tabular}{|l|c|cccc|}
\hline \multirow{2}{*}{ Variant } & \multicolumn{5}{|c|}{ Simulated Loss Rates (percent) } \\
\cline { 2 - 6 } & & \multicolumn{4}{|c|}{ At Loss Distribution Percentiles: } \\
\hline Base Case (see Table 1 for parameter values) & 0.63 & 1.87 & 2.71 & 3.04 & 3.87 \\
Base Case, replication factor doubled & 0.63 & 1.89 & 2.77 & 3.13 & 3.94 \\
Base Case, replication factor $=$ 30 for all grades & 0.63 & 1.85 & 2.71 & 3.09 & 3.85 \\
Base Case, replication factor = 80 for all grades & 0.63 & 1.88 & 2.74 & 3.11 & 3.88 \\
\hline
\end{tabular}

Table 3. Loss Rates for Portfolios With All Loans in a Single Grade

For comparison with remaining rows, the first row reports results for base case parameters except that a replication factor of 80 is applied to loans in all grades and years. Remaining rows report results when simulated portfolios are constrained to contain only loans to borrowers with the specified start-of-year rating, with other parameters identical to those of the base case apart from the replication factor of 80 .

\begin{tabular}{|l|ccccc|}
\hline \multirow{2}{*}{ Variant } & \multicolumn{5}{|c|}{ Simulated Loss Rates (percent) } \\
\cline { 2 - 7 } & \multicolumn{4}{|c}{ At Loss Distribution Percentiles: } \\
\hline Base Case (but replication factor is 80) & Mean & 95 & 99 & 99.5 & 99.9 \\
All loans rated A or better & 0.63 & 1.88 & 2.74 & 3.11 & 3.88 \\
All loans rated Baa & 0.00 & 0.00 & 0.13 & 0.26 & 0.67 \\
All loans rated Ba & 0.06 & 0.42 & 0.98 & 1.20 & 1.81 \\
All loans rated B & 0.53 & 1.95 & 2.96 & 3.36 & 4.19 \\
& 2.85 & 6.29 & 8.12 & 8.76 & 9.88 \\
\hline
\end{tabular}


Table 4. Loss Rates as the Fraction of Subordinated Loans Varies, Variable LGDs

In the exercises reported in this table, LGDs are permitted to vary randomly across individual credit events in a manner mimicking event-type and seniority-specific distributions from Society of Actuaries (1998). Mean LGDs for senior and subordinated defaults are 44 and 63 percent, respectively, and for senior and subordinated restructurings are 22 and 24 percent, respectively. Other parameters for the exercise are those of the base case.

\begin{tabular}{|l|c|cccr|}
\hline \multirow{2}{*}{ Variant } & \multicolumn{5}{|c|}{ Simulated Loss Rates (percent) } \\
\cline { 2 - 6 } & \multicolumn{4}{|c|}{ At Loss Distribution Percentiles: } \\
\hline Restructurings included, 0\% subordinated & 0.80 & 2.25 & 3.18 & 3.54 & 4.32 \\
Restructurings included, 20\% subordinated & 0.85 & 2.34 & 3.28 & 3.68 & 4.47 \\
Restructurings included, 40\% subordinated & 0.91 & 2.55 & 3.59 & 3.99 & 4.82 \\
Restructurings included, 60\% subordinated & 0.96 & 2.70 & 3.80 & 4.23 & 5.20 \\
Restructurings included, 80\% subordinated & 1.01 & 2.85 & 4.03 & 4.46 & 5.39 \\
\hline
\end{tabular}

Table 5. Loss Rates as the Fraction of Subordinated Loans Varies, Fixed LGDs

In the exercises reported in this table, LGDs are held fixed for each type of credit event and priority. LGD values for senior and subordinated defaults are 10 and 50 percent, respectively, and for senior and subordinated restructurings are 5 and 20 percent, respectively. Other parameters for the exercise are those of the base case.

\begin{tabular}{|l|ccccc|}
\hline \multirow{2}{*}{ Variant* } & \multicolumn{5}{|c|}{ Simulated Loss Rates (percent) } \\
\cline { 2 - 6 } & \multicolumn{4}{|c}{ At Loss Distribution Percentiles: } \\
\hline Restructurings included, 0\% subordinated & 0.18 & 0.48 & 0.64 & 0.71 & 0.84 \\
Restructurings included, 20\% subordinated & 0.31 & 0.88 & 1.31 & 1.50 & 1.87 \\
Restructurings included, 40\% subordinated & 0.45 & 1.26 & 1.83 & 2.04 & 2.50 \\
Restructurings included, 60\% subordinated & 0.58 & 1.64 & 2.28 & 2.52 & 3.09 \\
Restructurings included, 80\% subordinated & 0.72 & 1.97 & 2.68 & 2.97 & 3.54 \\
\hline
\end{tabular}


Table 6. Loss Rates For Different Degrees of Portfolio Granularity

The first and third through fifth rows report results for base-case parameters, but unlike in other tables simulated portfolios are considered to be complete when they contain the number of exposures specified in the Variant column, not when they reach the usual specified portfolio dollar size of $\$ 5$ billion. Portfolio size for the first row is similar to that of the usual base case. Portfolio size is varied in the third through fifth rows. In the second row, portfolio size is fixed at 500 loans, but individual loan dollar sizes are fixed at $\$ 10$ million each, whereas in other rows the distribution of dollar loan sizes relative to the approximately $\$ 5$ billion portfolio size mimics that of an actual large U.S. bank.

\begin{tabular}{|l|ccccc|}
\hline \multirow{2}{*}{ Variant } & \multicolumn{5}{|c|}{ Simulated Loss Rates (percent) } \\
\cline { 2 - 7 } & \multicolumn{4}{|c}{ At Loss Distribution Percentiles: } \\
Base case, but 500 loans, random sizes & Mean & 95 & 99 & 99.5 & 99.9 \\
Base case, but 500 loans, equal sizes & 0.67 & 2.01 & 2.98 & 3.39 & 4.34 \\
Base case, but 100 loans, random sizes & 0.66 & 1.73 & 2.37 & 2.58 & 2.98 \\
Base case, but 1000 loans, random sizes & 0.66 & 1.84 & 2.72 & 3.09 & 4.11 \\
Base case, but 2000 loans, random sizes & 0.66 & 1.80 & 2.67 & 3.10 & 3.93 \\
\hline
\end{tabular}

Table 7. $\quad$ Loss Rates For Different Loan-to-One-Borrower Limits

Parameters are those of the base case, except the loan-to-one borrower limits varies as specified (the limit for the base case is 3 percent).

\begin{tabular}{|l|ccccc|}
\hline \multirow{2}{*}{ Variant } & \multicolumn{5}{|c|}{ Simulated Loss Rates (percent) } \\
\cline { 2 - 7 } & \multicolumn{4}{|c}{ At Loss Distribution Percentiles: } \\
\hline Base case, no one-borrower limit & Mean & 95 & 99 & 99.5 & 99.9 \\
Base case, 5 percent one-borrower limit & 0.66 & 2.09 & 3.38 & 4.16 & 7.81 \\
Base case, 3 percent one-borrower limit & 0.66 & 2.11 & 3.14 & 3.55 & 4.43 \\
Base case, 2 percent one-borrower limit & 0.66 & 2.11 & 3.14 & 3.53 & 4.44 \\
Base case, 1 percent one-borrower limit & 0.66 & 2.03 & 2.97 & 3.34 & 4.10 \\
Base case, 0.5 percent one-borrower limit & 0.66 & 1.97 & 2.81 & 3.13 & 3.75 \\
\hline
\end{tabular}


Table 8. Loss Rates For Different Loan-to-One-Industry Limits, 39-Industry Classification

Parameters are those of the base case, but the loan-to-one-industry limit is varied from its usual value of 5 percent.

\begin{tabular}{|l|ccccc|}
\hline \multirow{2}{*}{ Variant } & \multicolumn{5}{|c|}{ Simulated Loss Rates (percent) } \\
\cline { 2 - 7 } & \multicolumn{5}{|c|}{ At Loss Distribution Percentiles: } \\
\hline Base case, no limit & Mean & 95 & 99 & 99.5 & 99.9 \\
Base case, 20 percent limit & 0.66 & 2.09 & 3.11 & 3.52 & 4.42 \\
Base case, 10 percent limit & 0.66 & 2.08 & 3.11 & 3.52 & 4.38 \\
Base case, 5 percent limit & 0.65 & 2.02 & 2.95 & 3.31 & 4.15 \\
\hline
\end{tabular}

Table 9. Loss Rates For Different Loan-to-One-Industry Limits, 20-Industry Classification

Parameters are those of the base case, but the loan-to-one-industry limit is varied and the Carey 20-industry classification scheme is used in enforcing the limit rather than the usual Carey 39industry scheme.

\begin{tabular}{|l|ccccc|}
\hline \multirow{2}{*}{ Variant } & \multicolumn{5}{|c|}{ Simulated Loss Rates (percent) } \\
\cline { 2 - 7 } & \multicolumn{4}{|c}{ At Loss Distribution Percentiles: } \\
\hline Base case, no limit & Mean & 95 & 99 & 99.5 & 99.9 \\
Base case, 30 percent limit & 0.66 & 2.10 & 3.13 & 3.52 & 4.41 \\
Base case, 20 percent limit & 0.66 & 2.09 & 3.10 & 3.52 & 4.43 \\
Base case, 10 percent limit & 0.66 & 2.09 & 3.08 & 3.50 & 4.38 \\
Base case, 7.5 percent limit & 0.64 & 1.95 & 2.84 & 3.18 & 4.00 \\
\hline
\end{tabular}


Table 10. Loss Rates When Restructurings as Well as Defaults are Included as Losses

Results in the first row are those for the base case, in which only actual defaults as recorded in Moody's database are considered as credit risk events. In the second and third rows, exposures are randomly designated as restructurings as described in the text. All simulated loans are senior, and simulated LGDs vary across loans such that their distributions mimic those reported in Society of Actuaries (1998) for defaults and restructurings (mean LGDs of 44 and 22 percent, respectively, see Section 5).

\begin{tabular}{|l|c|cccc|}
\hline \multirow{2}{*}{ Variant } & \multicolumn{5}{|c|}{ Simulated Loss Rates (percent) } \\
\cline { 2 - 6 } & \multicolumn{4}{|c|}{ At Loss Distribution Percentiles: } \\
\hline Base Case & Mean & 95 & 99 & 99.5 & 99.9 \\
1 simulated restructuring for every 3 defaults & 0.63 & 1.87 & 2.71 & 3.04 & 3.87 \\
1 simulated restructuring for every 2 defaults, & 0.75 & 2.10 & 2.98 & 3.32 & 4.16 \\
higher rate for junk loans & 0.80 & 2.24 & 3.18 & 3.53 & 4.37 \\
\hline
\end{tabular}

\section{Table 11. Effect of Fixed versus Variable LGDs}

Results are for an exercise in which simulated restructurings are created, similar to the case reported in the third row of Table 10. In the first row, LGDs vary across credit risk events by event type in a manner such that the distributions of LGDs mimic those reported in Society of Actuaries (1998). In the second row, LGDs for all credit events are held fixed at the mean values for defaults and restructurings, respectively (all simulated loans are senior).

\begin{tabular}{|l|c|cccc|}
\hline \multirow{2}{*}{ Variant } & \multicolumn{5}{|c|}{ Simulated Loss Rates (percent) } \\
\cline { 2 - 6 } & \multicolumn{4}{|c|}{ At Loss Distribution Percentiles: } \\
Restructurings included, realistic LGD variation & 0.80 & 2.23 & 3.15 & 3.51 & 4.29 \\
$\begin{array}{l}\text { Restructurings included, fixed LGDs (mean } \\
\text { values of the realistic distributions) }\end{array}$ & 0.81 & 2.16 & 2.91 & 3.17 & 3.74 \\
\hline
\end{tabular}




\section{Table 12. Tail Loss Rates Based on All Years, Good Years, and Bad Years}

This table reports results when the normal equal-weighting of experience years in the Moody's database is varied to put all weight on good or bad years, respectively, with bad experience years being 1970, 1986, and 1989-91 and good years being all others. Results in the first row are for the base case and are for comparison. The second and third rows restrict resampling to good and bad experience years, respectively, while maintaining the usual distribution of loans across grades in simulated portfolios. Remaining rows report results for good versus bad years when all loans are restricted to be in the grades Aaa through Baa3 (investment grade) or Ba1 through B3 (junk), respectively.

\begin{tabular}{|l|c|cccc|}
\hline \multirow{2}{*}{ Variant } & \multicolumn{5}{|c|}{ Simulated Loss Rates (percent) } \\
\cline { 2 - 6 } & \multicolumn{4}{|c}{ At Loss Distribution Percentiles: } \\
\hline Base distribution of grades, All years & Mean & 95 & 99 & 99.5 & 99.9 \\
Base distribution of grades, Good years only & 0.62 & 1.86 & 2.72 & 3.09 & 3.86 \\
Base distribution of grades, Bad years only & 0.47 & 1.36 & 2.04 & 2.34 & 3.07 \\
Investment-grade loans only, Good years only & 1.39 & 2.74 & 3.54 & 3.89 & 4.64 \\
Investment-grade loans only, Bad years only & 0.02 & 0.15 & 0.52 & 0.74 & 1.29 \\
Junk-grade loans only, Good years only & 0.12 & 0.64 & 1.25 & 1.51 & 2.27 \\
Junk-grade loans only, Bad years only & 0.93 & 2.26 & 3.06 & 3.39 & 4.18 \\
\hline
\end{tabular}


Figure 1. Stylized debt portfolio loss distribution.

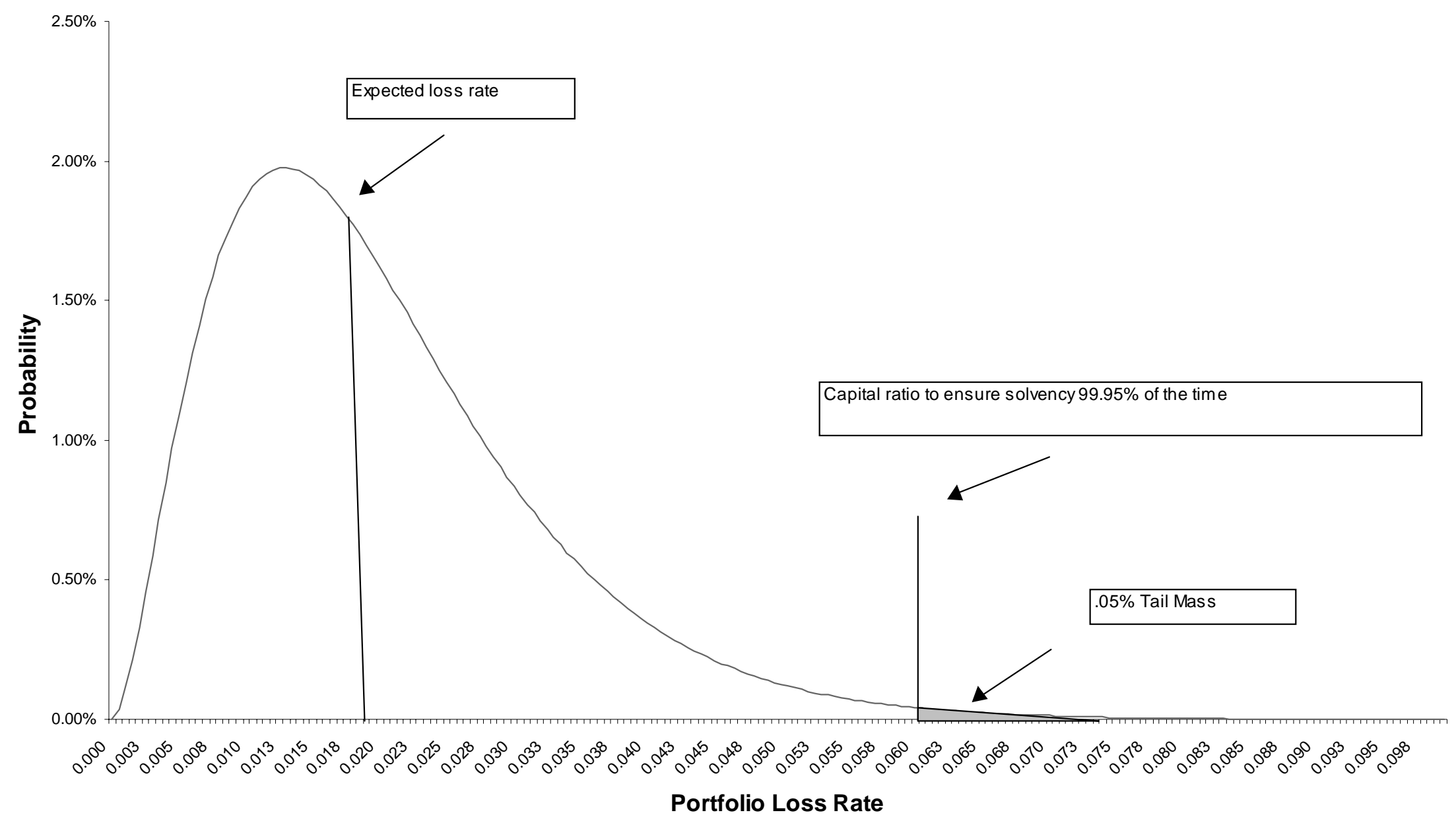




\section{Figure 2. Percentage error from linear capital specification}

Each bar represents the percentage deviation of approximated from directly measured loss rates at the $99^{\text {th }}$ percentile for a single exercise. Exercises differ in the fraction of loans in each grade. Results are shown for every possible permutation of grade mixes when fractions in each grade are varied in 20 percent increments. The linear method used to approximate capital is one typical of many internal rating approaches.

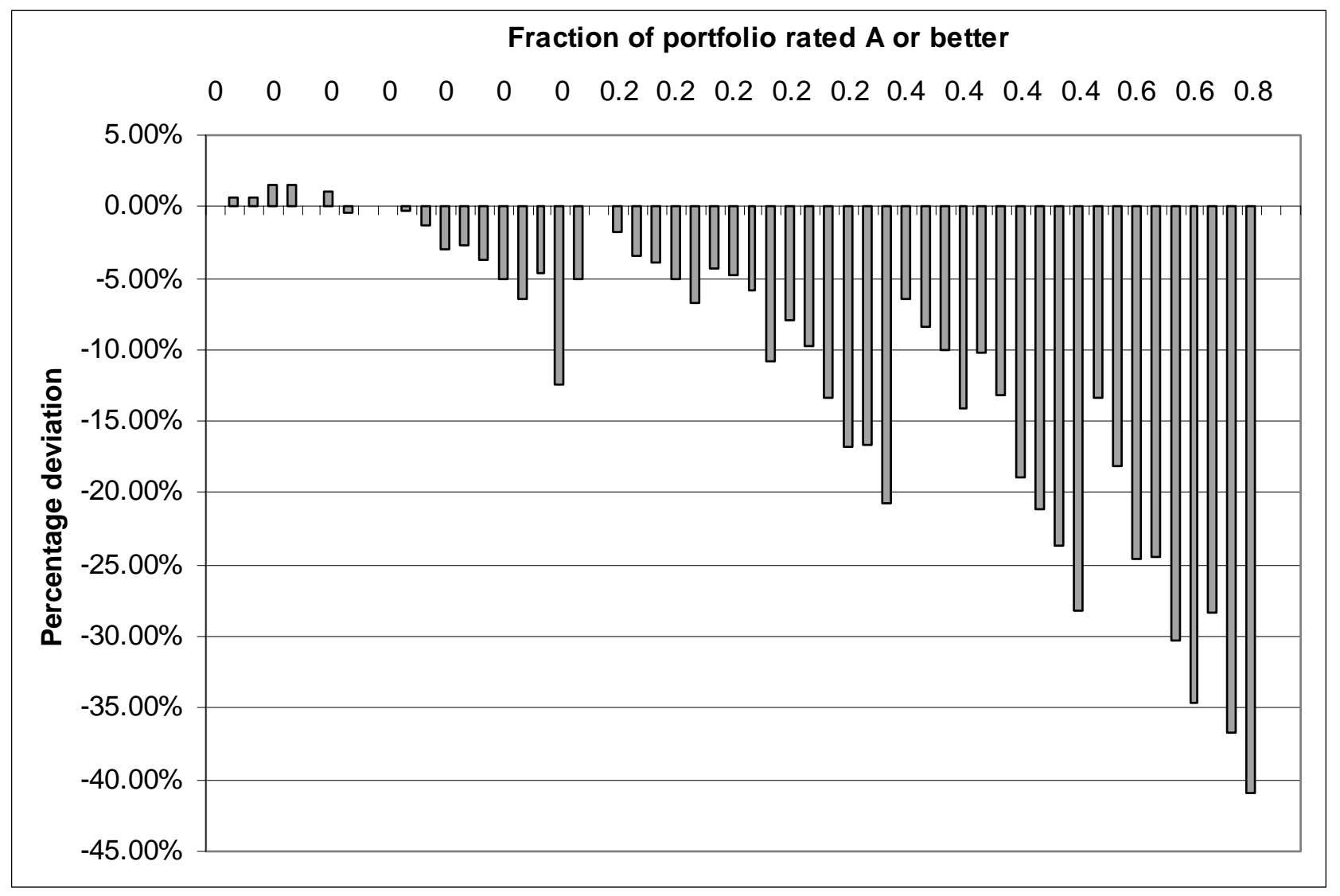


Figure 3. Absolute error from linear capital specification

Each bar represents the absolute deviation in percentage points of approximated from directly measured loss rates at the $99^{\text {th }}$ percentile for a single exercise. Exercises differ in the fraction of loans in each grade. Results are shown for every possible permutation of grade mixes when fractions in each grade are varied in 20 percent increments. The linear method used to approximate capital is one typical of many internal rating approaches.

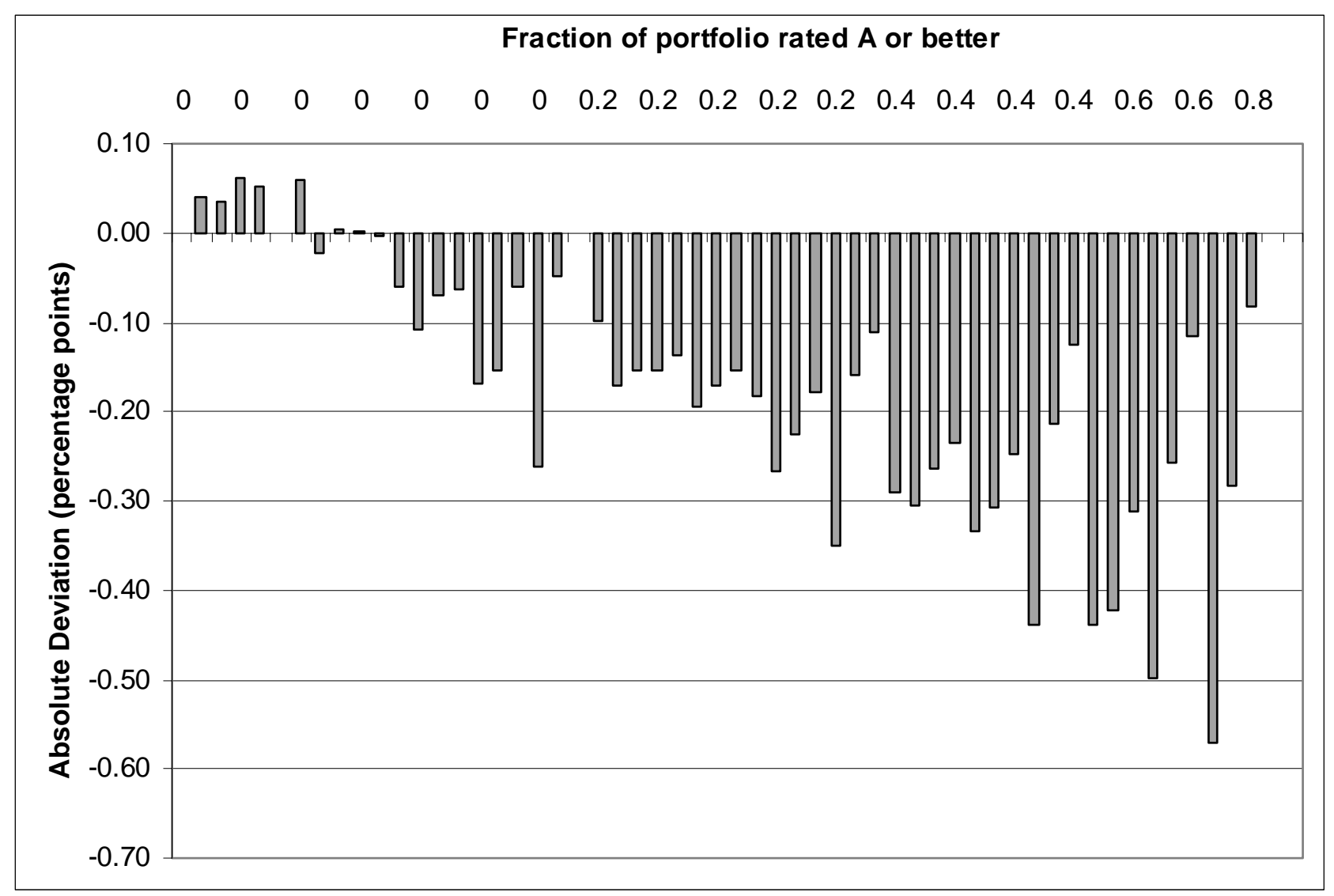

